\title{
Effects of Different Taekwondo Trainings on Children's Working Memory
}

\section{Farklı Taekwondo Antrenmanlarının Çocuklarda Çalışma Belleği Üzerine Etkisi}

Gülay Güler ${ }^{1} \quad$ iD https://orcid.org/0000-0003-4848-9303

Institute of Health Sciences, Hitit University, Çorum, Turkey

\author{
Yetkin Utku Kamuk (iD) https://orcid.org/0000-0001-5976-7503 \\ Faculty of Sport Sciences, Hitit University, Çorum, Turkey \\ Received: March 16, 2020 \\ Accepted: March 28, $2020 \quad$ Online Published: March 31, 2020 \\ DOI: $10.30655 /$ besad.2020.26 \\ https//doi.org/10.30655/besad.2020.26
}

\begin{abstract}
The aim of this study is to investigate the effects of participation in Taekwondo training on working memory in children aged 10 and 11 . In the province of Kocaeli, 74 children between the ages of 10-11 who just started Taekwondo and 28 children who did not take part in any training regularly, participated. The Ethics Committee approval was obtained from Hitit University Non-Interventional Researches Ethics Committee (2019-84) and the written institution permission was obtained from the sports club where the training sessions were held. The families of the children, who voluntarily accepted to participate in the study, were asked to sign the written consent form. Working Memory Scale, developed by Ergül, Yilmaz and Demir (2018), was used to collect the data. Since it was seen that the assumption of normality was not met as a result of Shapiro-Wilk test analysis, Mann-Whitney $U$ and One-Sample Wilcoxon tests were used for the analyzes. The subjects were divided into three groups; 37 (18 boys and 19 girls) as Poomsae, 37 (15 boys and 22 girls) as Kyorugi and 28 (14 boys and 14 girls) as control. As a result of the analysis of the data, it was found that there was a statistically significant decrease in the working memory scores of the subjects in the Kyorugi group, while the working memory in the Poomsae group was positively affected and the scores increased. Control group had no significant differences between tests. It was concluded that Poomsae training affected children's working memory positively but more studies are needed to investigate the causes of this impairment in the Kyorugi group.
\end{abstract}

Keywords: Exercise, training, martial arts

Öz

Bu çalışmanın amacı, Taekwondo antrenmanlarına katıımın 10 ve 11 yaşlarındaki çocukların çalışma bellekleri üzerindeki etkilerinin araştırılmasıdır. Çalışmaya, Kocaeli ilinde Taekwondo sporuna yeni başlayan 10-11 yaşlarındaki

${ }^{1}$ Corresponding Author: Gülay Güler

Hitit Üniversitesi, Sağlık Bilimleri Enstitüsü, Çorum, Turkey 
74 çocuk ve düzenli olarak herhangi bir spor yapmayan 28 çocuk katılmıştır. Çalışmanın yapılabilmesi için gerekli Etik Kurul izni Hitit Üniversitesi Girişimsel Olmayan Araştırmalar Etik Kurulu'ndan (2019-84), yazılı kurum izni ise antrenmanların gerçekleştirildiği spor kulübünden alınmıştır. Çalışmaya gönüllü olarak katıımı kabul eden çocukların ailelerinden bilgilendirilmiş veli/vasi onam formunu imzalamaları istenmiş, çalışmaya katııma yazılı olur vermeyen ailelerin çocukları çalışma kapsamına dahil edilmemiştir. Verilerin toplanması için Ergül, Yılmaz ve Demir (2018) tarafından geliştirilen Çalışma Belleği Ölçeği kullanılmıştır. Shapiro-Wilk testi analizi sonucunda normallik varsayımının karşılanmadığı görüldügünden, istatistiksel analizler için Mann-Whitney U ve tek örneklem Wilcoxon testleri kullanılmıştır. Çalışmaya katılan 102 katılımcıdan (47 erkek ve 55 kız) 37'si (18 erkek ve 19 kız) Poomsae, 37'si (15 erkek ve 22 kIz) Kyorugi ve 28'i (14 erkek ve 14 kIz) kontrol grubu olarak belirlenmiştir. Verilerin analizi sonucunda, Kyorugi grubundaki deneklerin çalışma belleği puanlarında istatistiksel olarak anlamlı düzeyde azalma olduğu, Poomsae grubunda ise çalışma belleğinin olumlu olarak etkilendiği ve puanlarda artış olduğu bulunmuştur. Kontrol grubunda ise hiçbir anlamlı değişiklik meydana gelmemiştir. Poomsae antrenmanlarının çocuklarda çalışma belleğini olumlu etkilediği ancak Kyorugi grubundaki bu kötüleşmenin nedenlerinin incelenmesi için daha fazla çalışmanın yapılmasına ihtiyaç duyulduğu sonucuna ulaşılmıştır.

Anahtar Kelimeler: antrenman, egzersiz, savunma sporları

\section{Giriş}

Bir mücadele sporu olan Taekwondo, bireylerin güven, sorumluluk, işbirliği, arkadaşlık ve liderlik gibi özelliklerinin gelişmesine katkı sağlayan ve ana vatanı Kore olan bir spordur (Karanfilci, Kabak, Hamamcılar ve Arslanoğlu, 2013). Teknik hareketlerden oluşan bu sporda, başarı için bütün kasların ve eklemlerin aktif halde bulunmasına intiyaç duyulmaktadır (Tel, 2008). Taekwondo sporu; Kyorugi (mücadele), Poomsae (hayali dövüş), Kyukpa (kırış) ve Hosinsul (yakın savuma) olarak dört disipline ayrılmaktadır fakat müsabakalar yalnızca ilk üç disiplinde yapılmaktadır. Kyorugi, çıplak el ve ayak kullanılarak hücum ve savunma tekniklerinin uygulandığı ve önceden belirlenmiş olan kurallara göre rakibe karşı üstün gelme amacı güden disiplindir. Poomsae, hücum ve savunma tekniklerini içeren ve hayali bir rakibe karşı yapılan el ve ayak teknikleri ile duruş, yön değiştirme ve hareketlerin açısının önemli olduğu performanstır. Kyukpa, çeşitli objelerin kırılması ile gerçekleştirilen ve Taekwonda sporunda yer alan güç ve tekniğin gösterildiği disiplindir. Hosinsul ise, bir yakın savunma sistemidir ve gerçek hayatta kavga anında kullanılabilecek tüm teknik hareketleri içermektedir ve resmi bir müsabakası yoktur (The Taekwondo WT Academy, 2020).

Kyorugi, iki rakibin Taekwondo tekniklerini kullanarak rakibi yenmeye çalıştıkları olimpik bir müsabakadır. Taekwondo sporundan bahsedildiğinde akla ilk gelen disiplin Kyorugi'dir. Bir gösteri disiplini olan Poomsae'nin dövüş sporları eğitiminde çok önemli bir noktada olmasına karşın, gerçek mücadelelerde kullanılabilirliği kısıtıdır. Bu kısıtıı̆̆ın nedeni, uygulamada gerçek bir rakibin olmamasıdır çünkü Poomsae hayali bir rakip ile mücadele olduğundan, gerçek bir savunma ve hücum becerilerine intiyaç yoktur. Bundan dolayı Poomsae prensipleri ve yöntemleri, Kyorugi'den farklılık göstermektedir (Lee ve Kim, 2007).

Tüm spor branşlarında olduğu gibi Taekwondo'da da bilişsel süreçler oldukça önemli bir yer tutmaktadır. Hareketlerin yapılması, koreografilerin hatırlanması, rakibin uyguladığı tekniğin akılda tutulması ve çevresel uyaranların bellekte işlenmesi gibi birçok işlem, bilişsel süreçler kullanılarak gerçekleştirilir. Bilişsel fonksiyonların iyi olması bellek ile ilişkilidir çünkü bilginin işlenmesi, merkezi sinir sistemine aktarılması, anlamlandırılması, diğer bilgilerle ilişkilendirilmesi ve kaydedilmesi belleğin kontrolündedir (Öymen Özak ve Pulat Gökmen, 2009). Kaydettiği bilgilerin ihtiyaç halinde geri getirilmesini sağlayan önemli bir mekanizma olan bellek, kısa süreli bellek (KSB) ve uzun süreli bellek (USB) olmak üzere iki bölümde incelenmektedir. Birincil bellek olarak da adlandırılan KSB, bilgiyi bir süreliğine depolamakta ancak bu bilgiler USB'ye aktarımadığında kısa sürede kaybolmaktadır (Leana, 2009). USB ise bilgileri anlamlandırarak kaydeden birimdir ve USB'teki bilgiler kalıc özelliğe 
sahiptir. Kompleks bir yapıya sahip olan USB'ye kaydedilen bilgilerin kalıcılığı, görsel ve işitsel uyaranlardan önemli ölçüde etkilenmektedir (Erberk Özen ve Rezaki, 2007).

USB'in depolama yeteneğinin belirli bir sınırı yoktur. USB, birbirinden farklı birçok karmaşık bilgiyi kaydedebilir ve kaydettiği karmaşık bilgileri intiyaç halinde çok kısa sürede geri çağırabilir (Korkmaz ve Mahiroğlu, 2007). Yeni bir bilginin USB'ye kaydedilmesi için önceki bilgilerin silinerek yeni bilgi için yer açılmasına gerek yoktur (Alp ve Ögüt Özdemir, 2007). Çalışma belleği, beynin yürütücü işlevlerinden biri olup, beynin kısa vadede intiyaç duyduğu bilginin kısa süreliğine tutulmasında ve daha sonra gerekli olan bilgilerin USB'e aktarılmasında ana rol oynamaktadır (Jaroslawska ve Rhodes, 2019). Temel bir zihinsel bileşen olan çalışma belleği, hem öğrenme hem de günlük işleri yapma açısından öneme sahiptir (Schweizer vd., 2019).

Çalışma belleği insanların beyninde geçici bir not defteri gibidir. Tuttuğu bilgiler sayesinde zihinsel süreçlerin devam ettirilebilmesi ve gerektiğinde bu bilgilerin bellekte mevcut diğer bilgilerle bağlanabilmesi için işlev görür (Daneman ve Merikle, 1996). Çalışma belleğinin asıl görevi, yapılan işle ilgili olarak, kullanılacak olan bilgilerin tutulmasıdır (Ashcraft ve Krause, 2007). Çalışma belleği, hayatın içerisinde bulunan uyarıcıların kaydedilmesini, saklanmasını ve intiyaç halinde tekrar kullanılabilmesini sağlamaktadır (Akoğlu ve Acarlar, 2014). Bazı araştırmacılar çalışma belleğini USB'ye bağımlı bir parça olarak görürken, bazıları ise çalışma belleğinin KSB ve USB'den bağımsız olarak çalıştığını öngörmüşlerdir (Dehn, 2008). Önceleri KSB olarak adlandırılan çalışma belleği, o anda çalışmakta olan belleği ifade eder. Bu bellekteki bilgiler bir dakikadan daha az süre saklanır ve KSB'in kapasitesi sınırlıdır. Çalışma belleği; problem çözme, muhakeme becerisi, anlama ve genel zeka alanları da dahil olmak üzere üst düzey bilişsel süreçlerde kilit bir role sahiptir (Doğan, 2011).

Çalışma belleği çocukluk döneminden yetişkinlik dönemine kadar sürekli olarak gelişim içindedir. Fakat bu gelişim yaşa ve diğer faktörlere göre değişiklik göstermektedir (Baddeley ve Hitch, 2007). Tüm yaş gruplarında, çalışma belleğinin gelişim kapasitelerinin ne olduğuna dair araştırmalar yapılmaktadır. Çocuklarda çalışma belleği kapasitesi ölçümü en erken dört yaşında yapılabilmektedir (Alloway, Gathercole, Kirkwood ve Elliott, 2009).

Sağlıklı bir toplumun oluşmasında en önemli faktörlerden biri olan spor, çocuklar üzerinde önemli etkilere sahiptir (Yavuz ve Özyürek, 2018). Oldukça yaygın olarak yapılan spor branşı olan Taekwondo, içerisinde yer alan hareketler sayesinde çocukların hem motor gelişimlerini desteklemekte hem de ruh sağlığının gelişmesine, karakter oluşumuna, sosyalleşmeye ve zorluklarla başa çıkma yeteneğinin kazandırılmasına katkıda bulunmaktadır (Şahin, Saraç, Çoban ve Coşkuner, 2011). Yapısında yer alan ilgi çeken hareketler ve çocukların hoşuna gidecek türden teknikler sayesinde Taekwondo (Gündoğdu, Bingöl, Mutlutürk ve Türkmen, 2012), motor gelişimin yanı sıra bilişsel fonksiyonların gelişimine de destek olan (Cho ve Roh, 2019) ve savunma sporları arasından en fazla tercih edilen spor dalıdır (Türkiye Taekwondo Federasyonu, 2019). Yukarıda verilen literatür bilgileri doğrultusunda bu çalışmanın amacı, Taekwondo sporunun farklı disiplinleri olan Kyorugi ve Poomsea antrenmanlarına 8 hafta süresince katılımın, 10-11 yaşlarındaki çocukların çalışma bellekleri üzerindeki etkilerinin incelenmesidir.

\section{Yöntem}

Deneysel araştırma modeli kullanılarak gerçekleştirilen bu çalışmaya, Kocaeli ilinde Taekwondo sporuna yeni başlayan 10-11 yaşlarındaki çocuklar katılmışlardır. Çalışmanın yapılabilmesi için gerekli Etik Kurul izni Hitit Üniversitesi Girişimsel Olmayan Araştırmalar Etik Kurulu'ndan (2019-84), yazılı kurum izni ise antrenmanların gerçekleştirildiği spor kulübünden alınmıştır. Çalışmaya gönüllü olarak 
katılımı kabul eden çocukların ailelerinden bilgilendirilmiş veli/vasi onam formunu imzalamaları istenmiş, çalışmaya katııma yazılı olur vermeyen ailelerin çocukları çalışma kapsamına dahil edilmemiştir. Çalışmaya katıımına gönüllü olur verilen 102 katıımcıdan (47 erkek ve 55 kız) 37'si (18 erkek ve 19 kIz) Poomsae, 37'si (15 erkek ve 22 kIz) Kyorugi ve 28'i (14 erkek ve 14 kIz) kontrol grubu olarak belirlenmiştir. Kyorugi ve Poomsae gruplarında yer alan denekler sekiz hafta boyunca, haftada 3 gün ve günde $90 \mathrm{dk}$. olmak üzere antrenmanlara katılmış, kontrol grubu ise planlı hiçbir egzersize iştirak etmemiştir. Tüm katılımcılara antrenmanların başlamasından önce ve 8 haftalık antrenman periyodunun sonunda olmak üzere toplam iki kez Çalışma Belleği Ölçeği (ÇBÖ) uygulanmıştır. Ergül, Yılmaz ve Demir (2018) tarafından geliştirilen ÇBÖ; rakam hatırlama alt ölçeği, sözcük hatırlama alt ölçeği, anlamsız sözcük hatırlama alt ölçeği, matris desen alt ölçeği, blok hatırlama alt ölçeği, geriye rakam hatırlama alt ölçeği, farklı olanı seçme alt ölçeği ve konum ayırt etme alt ölçeğinden oluşan sekiz alt ölçeğe sahiptir. ÇBÖ'nin Cronbach Alpha katsayısının 0,66 ile 0,99 arasında değiştiği görülmüştür. ÇBÖ'nin iç tutarlıığı orta-yüksek düzeydedir. ÇBÖ alt ölçekleri için ile test-tekrar test güvenirliği için Pearson Momentler Çarpımı Korelasyon Katsayısı 0,41 ile 0,83 arasındadır. ÇBÖ'nin test-tekrar test yöntemine dayalı güvenirliği orta-yüksek düzeydedir. Ölçeğin uygulanması, Ergül, Yılmaz ve Demir (2018) tarafından önerildiği şekilde gerçekleştirilmiştir.

Elde edilen verilerin istatistiksel analizi için SPSS 22.0 (IBM Corp., USA, Lisans: Hitit Üniversitesi) yazılımı kullanımıştır. Verilerin normal dağılıma uygunluğu Shapiro-Wilk testi kullanılarak analiz edilmiş ve verilerin normal dağııma uygun olmadığının görülmesi $(p<0,01)$ nedeniyle, parametrik olmayan analiz yöntemleri kullanılmıştır. İkili gruplar arasındaki farklııkların analizi için Mann-Whitney $U(M W U)$ testi, grupların ön ve son test değerleri arasındaki farkların karşılaştırılması için ise One Sample Wilcoxon testi kullanılmıştır. Tüm istatistiksel analizlerde anlamlılk düzeyi $p<0,05$ olarak belirlenmiştir.

\section{Bulgular}

Çalışmaya 47 erkek ve 55 kız olmak üzere toplam 102 denek katılmıştır. Deneklerin yaş ortalamaları Tablo 1'de verilmiştir. Tüm gruplardaki kız ve erkeklerin yaş ortalamaları birbirine çok yakındır ve 10,43 ile 10,89 yıl arasında değişiklik göstermektedir. Tablo 2'de deneklerin ÇBÖ'nden elde ettikleri ön ve son test puanlarının MWU testi kullanılarak karşılaştırılması sonucunda elde edilen veriler gösterilmektedir. Buna göre, Poomsae ve Kyorugi grubundaki deneklerin ön testte alt ölçeklerden elde ettikleri puanlar arasındaki anlamlı farkların; anlamsız sözcük hatırlama $(p<0,05)$, farklı olanı ayırt etme $(p<0,05)$ ve konum ayırt etme $(p<0,01)$ alt ölçeklerinde olduğu bulunmuştur. Diğer alt ölçeklerde ise. Poomsae ve Kyorugi gruplarının ön test değerleri arasında istatistiksel olarak anlamlı bir fark bulunmamıştır $(p>0,05)$. Son testlere bakıldığında, farklı olanı ayırt etme ve konum ayırt etme haricindeki diğer altı alt ölçekten elde edilen puanlarda istatistiksel olarak anlamlı farkların olduğu ( $p<0,01$ ve $p<0,05$ düzeylerinde) görülmüştür.

Tablo 1. Katıımcıların Gruplara Göre Dağılımı ve Yaş Ortalamaları

\begin{tabular}{ccccccc}
\hline & & & & Yaş (yıl) & \\
& & $n$ & En düşük & En yüksek & Ortalama & Standart sapma \\
\hline Poomsae & Erkek & 18 & 10,00 & 11,00 & 10,89 & 0,32 \\
& KIZ & 19 & 10,00 & 11,00 & 10,74 & 0,45 \\
\multirow{2}{*}{ Kyorugi } & Erkek & 15 & 10,00 & 11,00 & 10,73 & 0,46 \\
& KIZ & 22 & 10,00 & 11,00 & 10,59 & 0,50 \\
& Erkek & 14 & 10,00 & 11,00 & 10,43 & 0,51 \\
& KIZ & 14 & 10,00 & 11,00 & 10,57 & 0,51 \\
\hline
\end{tabular}


Tablo 2 ve Tablo 3 birlikte değerlendirildiğinde, son testlerde Poomsae grubunun ileriye rakam hatırlama alt ölçeği puanının Kyorugi grubunun puanından daha yüksek ve istatistiksel olarak anlamlı farka sahip olduğu $(Z=-2,187 ; p=0,029)$ görülmektedir.

Tablo 2. Ön ve Son Testlerde ÇBÖ Alt Ölçek Puanları Arasındaki Farkların MWU Testi ile İncelenmesi

\begin{tabular}{|c|c|c|c|c|c|c|c|}
\hline Ölçek & Grup & $n$ & $\begin{array}{c}\text { Sıra } \\
\text { Ortalaması }\end{array}$ & $\begin{array}{c}\text { Sıra } \\
\text { Toplamı }\end{array}$ & MWU & $z$ & $p$ \\
\hline \multirow[t]{2}{*}{ İleriye Rakam Hatırlama (Ön) } & Poomsae & 37 & 39,46 & 1460,00 & 612,000 & $-0,797$ & 0,425 \\
\hline & Kyorugi & 37 & 35.54 & 1315,00 & & & \\
\hline \multirow[t]{2}{*}{ İleriye Rakam Hatırlama (Son) } & Poomsae & 37 & 42,89 & 1587,00 & 485,000 & $-2,187$ & $0,029^{* *}$ \\
\hline & Kyorugi & 37 & 32,11 & 1188,00 & & & \\
\hline \multirow[t]{2}{*}{ Sözcük Hatırlama (Ön) } & Poomsae & 37 & 41,27 & 1527,00 & 545,000 & $-1,545$ & 0,122 \\
\hline & Kyorugi & 37 & 33.73 & 1248,00 & & & \\
\hline \multirow[t]{2}{*}{ Sözcük Hatırlama (Son) } & Poomsae & 37 & 45,20 & 1672,50 & 399,500 & $-3,138$ & $0,002^{*}$ \\
\hline & Kyorugi & 37 & 29,80 & 1102,50 & & & \\
\hline \multirow[t]{2}{*}{ Anlamsız Sözcük Hatırlama (Ön) } & Poomsae & 37 & 42,32 & 1566,00 & 506,000 & $-1,967$ & $0,049^{* *}$ \\
\hline & Kyorugi & 37 & 32,68 & 1209,00 & & & \\
\hline \multirow[t]{2}{*}{ Anlamsız Sözcük Hatırlama (Son) } & Poomsae & 37 & 43,03 & 1592,00 & 480,000 & $-2,270$ & $0,023^{* *}$ \\
\hline & Kyorugi & 37 & 31,97 & 1183,00 & & & \\
\hline \multirow[t]{2}{*}{ Geriye Rakam Hatırlama (Ön) } & Poomsae & 37 & 38,77 & 1434,50 & 637.500 & $-0,524$ & 0,600 \\
\hline & Kyorugi & 37 & 36,23 & 1340,50 & & & \\
\hline \multirow[t]{2}{*}{ Geriye Rakam Hatırlama (Ön) } & Poomsae & 37 & 42,46 & 1571,00 & 501,000 & $-2,034$ & $0,042^{* *}$ \\
\hline & Kyorugi & 37 & 32,54 & 1204,00 & & & \\
\hline \multirow[t]{2}{*}{ Farklı Olanı Ayırt Etme (Ön) } & Poomsae & 37 & 31,97 & 1183,00 & 480,000 & $-2,267$ & $0,023^{* *}$ \\
\hline & Kyorugi & 37 & 43,03 & 1592,00 & & & \\
\hline \multirow[t]{2}{*}{ Farklı Olanı Ayırt Etme (Son) } & Poomsae & 37 & 38,88 & 1438,50 & 633.500 & $-0,565$ & 0,572 \\
\hline & Kyorugi & 37 & 36,12 & 1336,50 & & & \\
\hline \multirow[t]{2}{*}{ Konum Ayırt Etme (Ön) } & Poomsae & 37 & 29,26 & 1082,50 & 379,500 & $-3,381$ & $0,001^{*}$ \\
\hline & Kyorugi & 37 & 45,74 & 1692,50 & & & \\
\hline \multirow[t]{2}{*}{ Konum Ayırt Etme (Son) } & Poomsae & 37 & 40,74 & 1507,50 & 564,500 & $-1,338$ & 0,181 \\
\hline & Kyorugi & 37 & 34,26 & 1267.50 & & & \\
\hline \multirow[t]{2}{*}{ Blok Hatırlama (Ön) } & Poomsae & 37 & 36,62 & 1355,00 & 652,000 & $-0,361$ & 0,718 \\
\hline & Kyorugi & 37 & 38,38 & 1420,00 & & & \\
\hline \multirow[t]{2}{*}{ Blok Hatırlama (Son) } & Poomsae & 37 & 45,42 & 1680,50 & 391,500 & $-3,244$ & $0,001^{*}$ \\
\hline & Kyorugi & 37 & 29,58 & 1094,50 & & & \\
\hline \multirow[t]{2}{*}{ Matris Desen (Ön) } & Poomsae & 37 & 36,22 & 1340,00 & 637,000 & $-0,525$ & 0,600 \\
\hline & Kyorugi & 37 & 38,78 & 1435,00 & & & \\
\hline \multirow[t]{2}{*}{ Matris Desen (Son) } & Poomsae & 37 & 46,66 & 1726,50 & 345.500 & $-3,718$ & $0,000^{*}$ \\
\hline & Kyorugi & 37 & 28,34 & 1048,50 & & & \\
\hline
\end{tabular}

${ }^{*} p<0,01 ;{ }^{* *} p<0,05$

Ayrıca, Kyorugi grubunun bu alt ölçekten elde ettiği ön test puanında azalma gerçekleştiği de görülmektedir. Benzer durum sözcük hatırlama, geriye rakam hatırlama, blok hatırlama ve matris desen alt ölçeklerinde de mevcuttur. Anlamsız sözcük hatırlama alt ölçeğinde ise her iki grubun puanlarında artış olmasına karşın. Poomsae grubunun puanlarının anlamlı bir şekilde daha yüksek olduğu ( $Z=-2,270 ; p=0,023$ ) görülmektedir (Tablo 2 ve Tablo 3). 
Tablo 3. Katılımcıların ÇBÖ Alt Ölçeklerinden Aldıkları Puanların Dağılımı

\begin{tabular}{|c|c|c|c|c|}
\hline \multirow[t]{3}{*}{ Alt Ölçekler } & \multicolumn{4}{|c|}{ Grup } \\
\hline & \multicolumn{2}{|c|}{ Poomsae $(n=37)$} & \multicolumn{2}{|c|}{ Kyorugi $(n=37)$} \\
\hline & Ortalama & Standart Sapma & Ortalama & Standart Sapma \\
\hline íleriye Rakam Hatırlama (Ön) & 6,43 & 1,92 & 6,03 & 1,64 \\
\hline İleriye Rakam Hatırlama (Son) & 6,65 & 2,07 & 5.51 & 1,68 \\
\hline Sözcük Hatırlama (Ön) & 4.57 & 1,34 & 4,00 & 1,43 \\
\hline Sözcük Hatırlama (Son) & 5,19 & 1,37 & 4,11 & 1,49 \\
\hline Anlamsız Sözcük Hatırlama (Ön) & 4,24 & 1,79 & 3,43 & 1,34 \\
\hline Anlamsız Sözcük Hatırlama (Son) & 4,59 & 1,59 & 3,70 & 1,15 \\
\hline Geriye Rakam Hatırlama (Ön) & 4,14 & 1,75 & 3.97 & 1,69 \\
\hline Geriye Rakam Hatırlama (Son) & 4,59 & 1,86 & 3,70 & 1,63 \\
\hline Farklı Olanı Ayırt Etme (Ön) & 3,14 & 1,70 & 3.97 & 1,17 \\
\hline Farklı Olanı Ayırt Etme (Son) & 3.73 & 1,48 & 3.57 & 1,34 \\
\hline Konum Ayırt Etme (Ön) & 1,43 & 1,21 & 2,43 & 1,17 \\
\hline Konum Ayırt Etme (Son) & 2,68 & 1,38 & 2,30 & 1,13 \\
\hline Blok Hatırlama (Ön) & 5,03 & 1,72 & 4,86 & 2,12 \\
\hline Blok Hatırlama (Son) & 6,05 & 1,20 & 4,81 & 1,61 \\
\hline Matris Desen (Ön) & 3,38 & 1,86 & 3.57 & 1,37 \\
\hline Matris Desen (Son) & 4.73 & 1,90 & 3,11 & 1,47 \\
\hline
\end{tabular}

Deneklerin ÇBÖ puanlarının cinsiyete göre farklıık gösterip göstermediği $M W U$ testi kullanılarak incelendiğinde (Tablo 4), ön testlerde yalnızca anlamsız sözcük hatırlama alt ölçeğinde erkekler lehine fark olduğu $(Z=-3,048 ; p=0,002)$ ancak bu farkın son testlerde ortaya çıkmadığı; ileriye rakam hatırlama ölçeği son testinde ise kızlar lehine anlamlı bir farkın ortaya çıktığı $(Z=-2,062 ; p=0,039)$ görülmektedir. Diğer alt ölçeklerden elde edilen ön test ve son test değerlerinde herhangi bir anlamlı farka rastlanılmamıştır $(p>0,05)$.

Tablo 4. Katılımcıların ÇBÖ Alt Ölçekleri Puanların MWU Testi Kullanılarak Karşılaştırılması

\begin{tabular}{lccccccc}
\hline \multicolumn{1}{c}{ Ölçek } & Cinsiyet & $\boldsymbol{n}$ & $\begin{array}{c}\text { Sıra } \\
\text { Ortalaması }\end{array}$ & $\begin{array}{c}\text { Sıra } \\
\text { Toplamı }\end{array}$ & MWU & $\boldsymbol{Z}$ & $\boldsymbol{p}$ \\
\hline İleriye Rakam Hatırlama (Son) & $\mathrm{E}$ & 33 & 31,83 & 1050,50 & 489,500 & $-2,062$ & $0,039^{*}$ \\
& $\mathrm{~K}$ & 41 & 42,06 & 1724,50 & & & \\
Anlamsız Sözcük Hatırlama (Ön) & $\mathrm{E}$ & 33 & 45,83 & 1512,50 & 401,500 & $-3,048$ & $0,002^{*}$ \\
& $\mathrm{~K}$ & 41 & 30,79 & 1262,50 & & & \\
\hline
\end{tabular}

Tablo 5'te, ÇBÖ'nden elde edilmiş olan ön test ve son test farklarının One Sample Wilcoxon testi kullanılarak yapılmış olan istatistiksel analizlere iliş̧in veriler sunulmuştur. Buna göre, kontrol grubunun ön ve son testleri arasında herhangi bir değişiklik olmadığı görülmüştür. Poomsae grubunun sözcük hatırlama, farklı olanı ayırt etme, konum ayırt etme, blok hatırlama ve matris desen alt ölçeklerinden elde ettikleri puanlarda istatistiksel olarak anlamlı bir artış olduğu $(p<0,01)$; ileriye rakam hatırlama, anlamsız sözcük hatırlama ve geriye rakam hatırlama alt ölçeklerinde istatistiksel olarak anlamlı bir değişikliğin gerçekleşmediği $(p>0,05)$ anlaşılmaktadır. Kyorugi grubunun sözcük hatırlama ve anlamsız sözcük hatırlama puanlarında artış olduğu ancak bunun istatistiksel olarak anlamlı olmaya yetecek düzeyde gerçekleşmediği $(p>0,05)$, diğer tüm alt ölçek puanlarında ise gerileme olduğu görülmektedir. Ileriye rakam hatılama, farklı olanı ayırt etme ve matris desen alt 
ölçeklerindeki gerilemenin istatistiksel olarak anlamlı düzeyde gerçekleştiği $(p<0,05)$, diğer alt ölçeklerdeki gerilemenin anlamlı düzeyde olmaya yetecek miktarda olmadığı $(p>0,05)$ görülmüştür.

Tablo 5. ÇBÖ Alt Ölçeklerinden Alınan Puan Farklarının One Sample Wilcoxon Testi ile Incelenmesi

\begin{tabular}{|c|c|c|c|c|c|c|}
\hline \multirow[b]{2}{*}{ Değişkenler } & \multicolumn{2}{|c|}{ Poomsae } & \multicolumn{2}{|c|}{ Kyorugi } & \multicolumn{2}{|c|}{ Kontrol } \\
\hline & $\begin{array}{c}\text { Test } \\
\text { istatistiği }\end{array}$ & $p$ & $\begin{array}{c}\text { Test } \\
\text { istatistiği }\end{array}$ & $p$ & $\begin{array}{c}\text { Test } \\
\text { istatistiği }\end{array}$ & $p$ \\
\hline İleriye Rakam Hatırlama & 1,217 & 0,224 & $-3,201$ & $0,001^{*}$ & 0,330 & 0,741 \\
\hline Sözcük Hatırlama & 3,319 & $0,002^{*}$ & 0,579 & 0,563 & 0,018 & 0,986 \\
\hline Anlamsız Sözcük Hatırlama & 0,916 & 0,360 & 1,134 & 0,257 & 0,410 & 0,682 \\
\hline Geriye Rakam Hatırlama & 1,590 & 0,112 & $-1,577$ & 0,115 & $-1,155$ & 0,248 \\
\hline Farklı Olanı Ayırt Etme & 2,874 & $0,004^{*}$ & $-2,277$ & $0,023^{* *}$ & 1,385 & 0,166 \\
\hline Konum Ayırt Etme & 4,259 & $0,000^{*}$ & $-0,826$ & 0,409 & 1,870 & 0,062 \\
\hline Blok Hatırlama & 3,423 & $0,001^{*}$ & $-0,322$ & 0,748 & $-0,018$ & 0,986 \\
\hline Matris Desen & 3,678 & $0,000^{*}$ & $-2,054$ & $0,040^{* *}$ & 0,894 & 0,371 \\
\hline
\end{tabular}

${ }^{*} p<0,01 ;{ }^{* *} p<0,05$

Şekil 1'de, çalışmaya katılan tüm grupların ölçeklerden aldıkları ön ve son test puanlarına ait bar grafiği verilmiştir. Her bir grubun ön ve son test değerlerine bakılarak, verilerdeki değişikliklerin yönü ve miktarı görülebilmektedir. Genel olarak kontrol grubunun ön ve son test değerlerinde fark olmadığı görülürken, Poomsae grubundaki genel artış eğilimi göze çarpmaktadır. Kyorugi grubunun değerlerinde ise genel bir azalmanın var olduğu da açıkça anlaşılmaktadır.

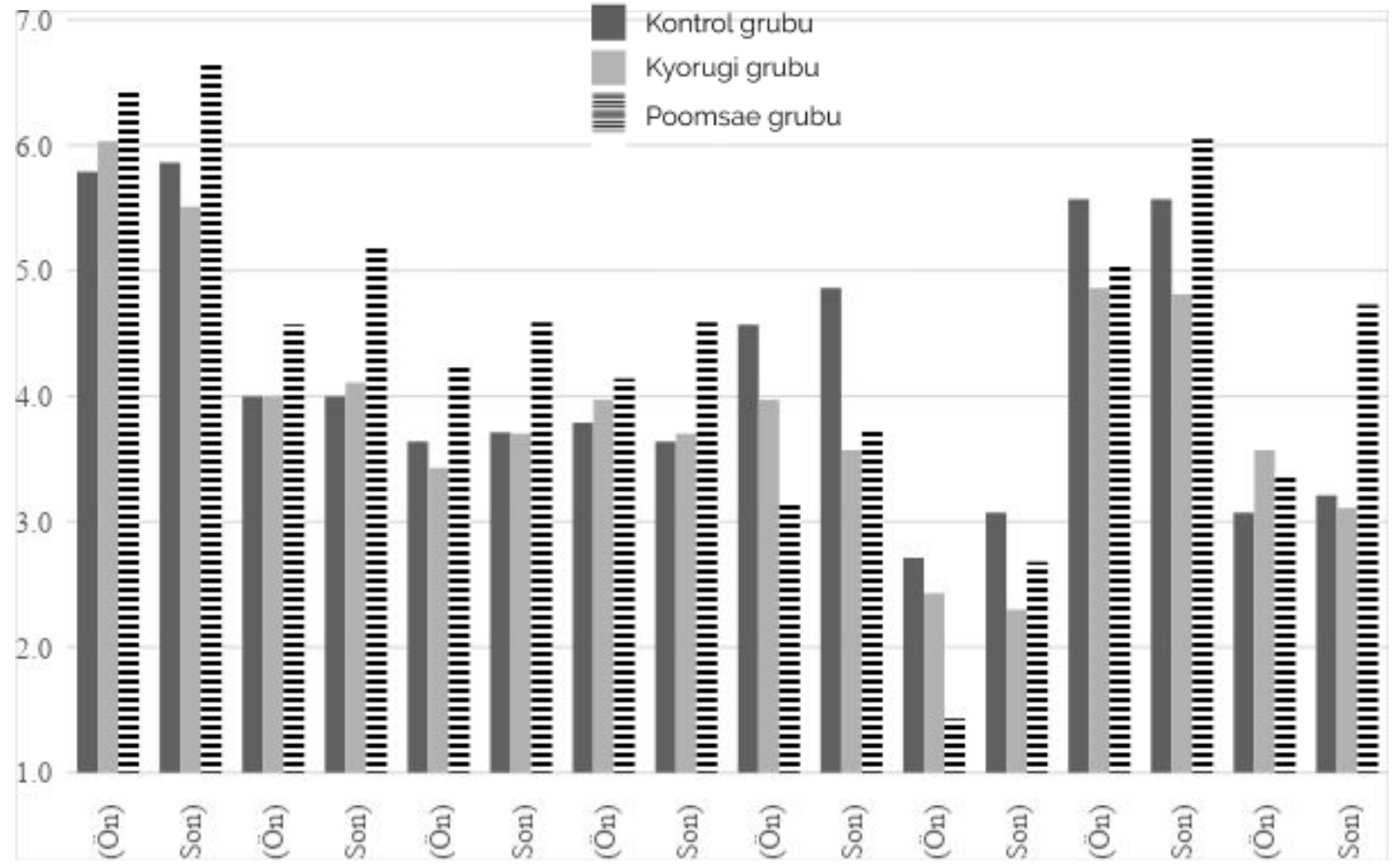

Şekil 1. Gruplara Göre Ön ve Son Testlerden Alınan Puanların Dağılımı 


\section{Tartışma}

Mevcut çalışmada, 10-11 yaşlarındaki çocuklara uygulanan Poomsae ve Kyorugi antrenmanlarının "Çalışma Belleği" üzerindeki etkileri incelenmiştir. Literatür incelendiğinde, ülkemizde Kyorugi ve Poomsae antrenmanlarının çalışma belleğini ne şekilde etkilediğinin araştırıldığı herhangi bir çalışmayla karşılaşılmamıştır. Öte yandan, uluslararası alanda ise Poomsae antrenmanlarının çalışma belleği üzerindeki etkisinin ne olduğunun incelendiği yalnızca bir çalışmaya rastlanmıştır. Montero-Briceno ve Castillo-Hernandez (2017) tarafından gerçekleştirilmiş olan bu çalışmada, Kosta Rika Cumhuriyeti'nde 9-11 yaşları arasındaki 48 sporcuya 6 hafta boyunca Poomsae antrenmanları yaptırımış ve bu antrenmanların çalışma bellekleri üzerindeki etkileri incelenmiştir. Bu çalışma sonuçlarına göre, Poomsae yapan sporcuların çalışma belleklerindeki gelişimin, Poomsae antrenmanlarına katılmayanlara göre istatistiksel olarak anlamlı şekilde iyi olduğu bildirilmiştir. Bu çalışmadan elde edilen sonuçlar ile mevcut çalışmadan elde edilen sonuçlar uyum göstermektedir. Mevcut çalışma sonuçlarına göre, katıımcıların Poomsae antrenmanları sonrasında çalışma belleklerinde istatistiksel olarak anlamlı düzeyde iyileşme gerçekleştiği ortaya konulmuştur. Mevcut çalışmadan elde edilen verilerin kıyaslanabileceği benzer çalışmaların literatürde mevcut olmaması, karşılaştırma yapılmasını oldukça zorlaştırmaktadır. Ancak, örtüşen çalışmalar olmasa dahi, egzersiz ve fiziksel aktivitenin çalışma belleği üzerindeki etkilerinin neler olduğuna dair yapılan çalışmalardan elde edilen sonuçlar aşağıdaki bölümde verilmiştir.

Çalışma belleği ile Taekwondo branşı arasındaki ilişkinin incelenmesine yönelik olarak yapılan çalışmaların tek örnekle kısıtlı olmasına karşın, çalışma belleği ile egzersize bağlı diğer faktörler arasındaki ilişkilerin incelendiği çalışmaların literatürde mevcut olduğu görülmüştür. Bu çalışmalardan birinde, 9-11 yaşları arasındaki 79 çocuğa kademeli olarak artan egzersiz testleri uygulanmış, aerobik düzeyleri iyi olan çocukların akademik performanslarının ve çalışma belleği puanlarının daha yüksek olduğu gösterilmiştir (Kao, Westfall, Parks, Pontifex ve Hillman, 2016). Bir başka çalışmada ise, 7-11 yaşları arasında olan fazla kilolu 171 sedanter çocuk üzerinde egzersizin bilişsel gelişim üzerindeki etkisi araştırılmış ve bu maksatla 3 farklı grup oluşturularak her gruba farklı egzersiz planları uygulanmıştır. Araştırma sonucunda egzersiz süresi daha fazla olan grubun bilişsel gelişim seviyelerinin pozitif yönde arttığı gözlemlenmiştir (Davis vd., 2011). Gallotta vd. (2012) tarafından italya'da yapılan başka bir çalışmada ise 8-11 yaşları arasındaki toplam 138 çocuk üzerinde fiziksel aktivitenin bilişsel performansı arttırıp arttırmadığı incelenmiş ve fiziksel olarak aktif olan çocukların bilişsel performanslarında olumlu yönde bir gelişim olduğu görülmüştür. Raine vd. (2013), 9 ve 10 yaşlarındaki toplam 48 çocuğun katılımıyla gerçekleştirdikleri bir çalışmada, fiziksel uygunluk seviyesinin ezberleme performansına etkisini incelemişler ve fiziksel uygunluk seviyesi yüksek olan çocukların ezberleme yeteneklerinin iyi seviyede olduğunu tespit etmişlerdir. Chaddock vd. (2010) tarafından gerçekleştirilen bir başka araştırmada ise 9-11 yaşları arasındaki 49 çocuğun hipokampüs bölgelerinin büyüklükleri incelenmiştir. Araştırma sonuçlarına göre, fiziksel olarak aktif olan çocukların, aktif olmayanlara kıyasla yaklaşık \%12 oranında daha büyük hipokampüse sahip oldukları görülmüştür. Bunun nedeninin, fiziksel olarak aktif olan çocukların oksijen kullanma veriminin daha yüksek ve hipokampüs hacimlerinin de daha büyük olduğu belirlenmiştir.

Chaddock-Heyman vd. (2014) tarafından yapılan bir çalışmanın sonuçlarına göre, 9-10 yaş aralığında ve fiziksel egzersiz yapan çocukların aktif olmayanlara kıyasla okuma, öğrenme, dil becerisi ve hafıza performanslarının daha iyi olduğu ve aradaki farkların istatistiksel olarak anlamlı düzeyde gerçekleştiği bildirilmiştir. Literatürde, çalışma belleği ve aktivite ilişkisinin incelendiği çalışmaların sadece çocuklarla sınırlı olmadığı görülmektedir. Ingilterede 475.397 kişinin katılımıyla bedensel gücün ve fiziksel uygunluğun, erişkin bireylerde beynin fonksiyonel işleyişine etkisinin araştırıldığı 
çalışmanın sonuçlarına göre, bedensel güce ve fiziksel uygunluğa sahip olan kişilerin beyin fonksiyonlarındaki işleyişin daha iyi olduğu belirlenmiştir (Firth vd., 2018). Yaşı bireyler üzerinde gerçekleştirilen farklı bir çalışmada, fiziksel egzersizlerin çalışma belleğini önemli ölçüde arttırdığı ve başlangıç seviyesinde olan Alzheimer hastalarının bilişsel etkinliklerde diğerlerine oranla daha iyi oldukları bildirilmiştir (Alfini, Weiss, Nielson, Verber ve Smith, 2019).

\section{Sonuç}

Kyorugi ve Poomsae antrenmanlarına katıımın çalışma belleği üzerindeki etkilerinin araştırıldı̆ı bu çalışma sonucunda, Poomsae antrenmanlarının 10-11 yaşlarındaki çocukların çalışma belleklerinde istatistiksel olarak anlamlı gelişime neden olduğu bulunmuştur. Özellikle sözcük hatırlama, farklı olanı ayırt etme, konum ayırt etme, blok hatırlama ve matris desen performanslarında istatistiksel olarak anlamlı düzeyde artış gerçekleşmiştir. Kontrol grubunun çalışma belleği puanlarında istatistiksel olarak anlamlı herhangi bir değişiklik gerçekleşmezken, Kyorugi grubunun çalışma belleği puanlarında azalma olduğu ve bu azalmanın ileriye rakam hatırlama, farklı olanı ayırt etme ve matris desen puanlarında istatistiksel olarak anlamlı düzeyde gerçekleştiği, diğer ölçeklerde farkların istatistiksel olarak anlamlı olmaya yetecek düzeyde olmadığı görülmüştür. Literatürde, fiziksel olarak aktif olmanın ve egzersizin çalışma belleği üzerindeki faydalarının gösterilmiş olmasına karşın bu çalışmadan elde edilen aksi yöndeki bulguların test edilmesi için daha fazla çalışmanın yapılmasına intiyaç duyulduğu sonucuna ulaşılmıştır.

Literatürde, Taekwondo ve çalışma belleği arasındaki ilişkinin incelendiği çalışmalar oldukça kısıtlı olduğundan, araştırmacıların bundan sonraki çalışmalarda çalışma belleği ile diğer mücadele sporlarının çalışma belleği üzerindeki etkilerini incelemelerinin konunun daha iyi anlaşııması açısından fayda sağlayacağı düşünülmektedir. Bununla birlikte, çalışma belleğinin oksijen kullanım kapasitesinden etkilenme düzeyinin incelenmesi de çalışma kapsamı içerisine dahil edilebilir.

\section{Kaynakça}

Akoğlu, G. \& Acarlar, F. (2014). Gelişimsel dil bozukluklarında söz dizimi anlama ve sözel çalışma belleği ilişkisinin incelenmesi. Türk Psikoloji Dergisi, 29(73), 89-103.

Alfini, A.J., Weiss, L.R., Nielson, K.A., Verber, M.D. \& Smith J.C. (2019). Resting cerebral blood flow after exercise training in mild cognitive Impairment. $J$ Alzheimers Dis, 67(2), 671-684. doi:10.3233/JAD-180728.

Alloway, T.P., Gathercole, S.E., Kirkwood, H. \& Elliott, J. (2009). The working memory rating scale: A classroom-based behavioral assessment of working memory. Learning and Individual Differences, 19, 242-245.

Alp, I.E. \& Ögüt Özdemir, B. (2007). Çocuklarda akıcı zekanın (Gf) bilgi işleme hızı, kısa süreli bellek ve çalışma belleği kapasitesi ile ilişkisi. Türk Psikoloji Dergisi, 22(60), 1-15.

Aschraft, M.H. \& Krause, J.A. (2007). Working memory, math performance, and math anxiety. Psychonomic Bulletin and Review, 14(2), 243-248.

Baddeley, A. \& Hitch, G. (2007). Working Memory. In: The Cognitive Neuroscience of Working Memory (Editors: N. Osaka, RH Logie and M D'Esposito). Oxford: Oxford University Press.

Chaddock, L., Erickson, K.I., Prakash, R.S., Kim, J.S., Voss, M.W., VanPatter, M., Pontifex, M.B., Raine, L.B., Konkel, A., Hillman, C.H., Cohen, N.J. \& Kramer, A.F. (2010). A neuroimaging investigation of the association between aerobic fitness, hippocampal volume, and memory performance in preadolescent children. Brain Res, 28(1358), 172-183. doi: 10.1016/j.brainres.2010.08.049. 
Chaddock-Heyman, L., Erickson, K.I., Holtrop, J.L., Voss, M.W., Pontifex, M.B., Raine, L.B., Hillman, C.H. \& Kramer, A.F. (2014). Aerobic fitness is associated with greater white matter integrity in children. Frontiers in Human Neuroscience, 8(584), 1-7. doi: 10.3389/fnhum.2014.00584.

Cho, S.Y. \& Roh, H.T. (2019). Taekwondo enhances cognitive function as a result of increased neurotrophic growth factors in elderly women. International Journal of Environmental Research and Public Health, 16(962), 1-12.

Daneman, M. \& Merikle, P.M. (1996). Working memory and language comprehension: A meta-analysis. Psychonomic Bulletin and Review, 3(4), 422-433.

Davis, C.L., Tomporowski, P.D., McDowell, J.E., Austin, B.P., Miller, P.H., Yanasak, N.E., Allison, J.D. \& Naglieri, J.A. (2011). Exercise Improves executive function and achievement and alters brain activation in overweight children: a randomized controlled trial. Health Psychol, 30(1), 91.98. doi: $10.1037 / \mathrm{a} 0021766$.

Dehn, M.J. (2008). Working Memory and Academic Learning: Assessment and Intervention. John Wiley and Sons: New Jersey.

Doğan, M. (2011). Çocuklarda çalışma belleği, akademik öğrenme ve öğrenme yetersizlikleri. Türk Psikoloji Yazıları, 14(27), 48-65.

Erberk Özen, N. \& Rezaki, M. (2007). Prefrontal korteks: Bellek işlevi ve bunama ilişkisi. Türk Psikiyatri Dergisi, 18(3), 262-269.

Ergül, C., Yılmaz, Ç.Ö. \& Demir, E. (2018). 5-10 yaş grubu çocuklara yönelik geliştirilmiş çalışma belleği ölçeğinin geçerlik ve güvenirliği. Eğitimde Kuram ve Uygulama, 14(2), 187-214.

Firth, J., Stubbs, B., Vancampfort, D., Firth, J.A., Large, M., Rosenbaum, S., Hallgren, M., Ward, P.B., Sarris, J. \& Yung, A.R. (2018). Grip strength is associated with cognitive performance in schizophrenia and the general population: a UK biobank study of 476559 participants. Schizophrenia Bulletin, 44, 728-736.

Gallotta, M.C., Guidetti, L., Franciosi, E., Emerenziani, G.P., Bonavolonta, V. \& Baldari, C. (2012). Effects of varying type of exertion on children's attention capacity. Medicine and Science in Sports and Exercise, 44(3), 550-555. doi: 10.1249/MSS.0b013e3182305552.

Gündoğdu, C., Bingöl, H., Mutlutürk, N. \& Türkmen, M. (2011). Üniversitelerde Öğrenim Gören Taekwondo Milli Takım Sporcularının Sosyo Ekonomik Durumları ile Bu Branşa Katıım Nedenlerinin Araştırılması. Celal Bayar Üniversitesi Beden Eğitimi ve Spor Bilimleri Dergisi, 5(3), 119-125.

Jaroslawska, A.J. \& Rhodes, S. (2019). Adult age differences in the effects of processing on storage in working memory: a meta-analysis. Psychology and Aging, 34(4), 512-530.

Kao, S.C., Westfall, D.R., Parks, A.C., Pontifex, M.B. \& Hillman, C.H. (2016). Muscular and aerobic fitness, working memory, and academic achievement in children. Medicine and Science in Sports and Exercise 49(3), 500-508. doi: 10.1249/MSS.0000000000001132

Karanfilci, M., Kabak, B., Hamamcılar, O. \& Arslanoğlu, E. (2013). Taekwondoda Spor Yaralanmaları ve Çözüm Önerileri. Neyir Matbaacılık: Ankara.

Korkmaz, Ö. \& Mahiroğlu, A. (2007). Beyin, bellek ve öğrenme. Kastamonu Eğitim Dergisi, 15(1), 93-104.

Leana, M.Z. (2009). Üstün ve normal öğrencilerin yönetici işlevlerinin ve çalışma belleklerinin değerlendirilmesi ve intiyaçlarına yönelik eğitim programının uygulanması. Doktora Tezi. istanbul Üniversitesi Sosyal Bilimler Enstitüsü.

Lee, K.H. \& Kim, S.H. (2007). Complete Taekwondo Poomsae. Turtle Press: Santa Fe.

Montero-Briceno, S. \& Castillo-Hernandez, I. (2017). Taekwondo practice Improves working memory in sedentary children. Medicine and Science in Sports and Exercise 49(5S), 301. doi: 10.1249/01.mss.0000517689.84019.b4

Öymen Özak, N. \& Pulat Gökmen, G. (2009). Bellek ve mekan üzerine bir model önerisi. iTü Dergisi, 8(2), 145-155. 
Raine, L.B., Lee, H.K., Saliba, B.J., Chaddock-Heyman, L., Hillman, C.H. \& Kramer, A.F. (2013). The influence of childhood aerobic fitness on learning and memory. PloS ONE, 8(9): e72666. doi: 10.137/journal.pone.0072666.

Schweizer, S., Satpute, A.B., Atzil, S., Field, A.P., Hitchcock, C., Black, M., Barrett, L.F. \& Dagleish, T. (2019). The impact of affective information on working memory: a pair of meta-analytic reviews of behavioral and neuroimaging evidence. Physiological Bulletin, 145(6), 566-609.

Şahin, M., Saraç, H., Çoban, O. \& Coşkuner, Z. (2011). Taekwondo antrenmanlarının çocukların motor gelişim düzeylerine etkisinin incelenmesi. Spor ve Performans Araştırmaları Dergisi, 3(1), 5-14.

Tel, M. (2008). Bir spor dalı olarak Taekwondo. e-Journal of New World Sciences Academy Health Sciences, 3(4), 194-202.

The Taekwondo WT Academy of the Kyrgyz Republic. (02 Ocak 2020). Erişim adresi: http://taekwondo-wtf.kg/en/taekwondo-disciplines/

Türkiye Taekwondo Federasyonu. (5 Kasım 2019). Erişim adresi: http://www.turkiyetaekwondofed.gov.tr/

Yavuz, N.F. \& Özyürek, A. (2018). Effects of physical education and sport activities on motor skills of preschool children. Karaelmas Journal of Educational Sciences, 6, 40-50.

Yazar notu: Bu çalışma, Gülay Güler'in "Taekwondo Antrenmanlarının Çocuklarda Çalışma Belleği Üzerine Etkisi" başııklı lisansüstü tez çalışması kapsamında üretilmiştir. 